\title{
Higher thermal resistance of corals in the global marine biodiversity center
}

Tim McClanahan ${ }^{1}$, Joseph Maina ${ }^{2}$, Emily Darling ${ }^{1}$, Stephanie D'agata ${ }^{3}$, Nyawira Muthiga $^{4}$, Julien Leblond ${ }^{5}$, Rohan Arthur ${ }^{6}$, Stacy Jupiter ${ }^{1}$, Shaun Wilson ${ }^{7}$, Sangeeta Mangubhai ${ }^{1}$, Ali Ussi ${ }^{8}$, Mireille Guillaume ${ }^{8}$, Austin Humphries ${ }^{9}$, Vardhan Patankar ${ }^{10}$, George Shedrawi ${ }^{11}$, Julius Pagu ${ }^{12}$, January Ndagala ${ }^{13}$, and Gabriel Grimsditch ${ }^{14}$

${ }^{1}$ Wildlife Conservation Society

${ }^{2}$ Macquarie University

${ }^{3}$ Macquire University

${ }^{4}$ Wildlife Conservation Society Kenya Mombasa

${ }^{5}$ Wildlife Conservation Society Madagascar

${ }^{6}$ Nature Conservation Foundation

${ }^{7}$ Government of Western Australia Department of Parks and Wildlife

${ }^{8}$ The State University of Zanzibar School of Natural and Social Sciences

${ }^{9}$ University of Rhode Island

${ }^{10}$ Wildlife Conservation Society India

${ }^{11}$ Curtin University Bentley Campus

${ }^{12}$ Mafia Island Marine Park

${ }^{13}$ Tanga Coelacanth Marine Park

${ }^{14}$ IUCN Maldives

May 5, 2020

\begin{abstract}
Predictions for the future of coral reef are largely based on thermal exposure and poorly account for geographic variation in biological sensitivity and resistance to thermal stress. Based on the ratio of thermal exposure and sensitivity, geographic variability of coral resistance was estimated during the 2016 global-bleaching event. Exposure was estimated as historical cumulative excess summer heat (CTA) and a multivariate index of SST, light, and water flow (CE). Site sensitivity was estimated for 226 sites using coordinated bleaching observations. Site resistance was evaluated by 128 possible models for the influences of geography, historical SST variation, coral cover, and number of coral genera. Most factors were statistically significant but the strongest factor was geography - Coral Triangle having higher resistance than non-Coral Triangle sites. Consequently, future predictions of thermal stress will need to account for strong geographic differences in acclimation/adaptation.
\end{abstract}

\section{Introduction}

The capacity of corals to adapt to climate change is among the Earth's most pressing environmental needs (Hughes et al. 2017). Localized studies have shown that corals acclimatize or adapt by changing protein expressions (Palumbi et al. 2014), switching of symbionts in variable sea-surface temperature (SST) environments (Boulette et al,. 2016; Safaie et al. 2018; Sully et al. 2019), and after experiencing warm-SST anomalies (Guest et al. 2012; McClanahan 2017; Hughes et al. 2019a). However, the resistance (=exposure/sensitivity) of scleractinian corals at large spatial scales of variability is only slowly being understood 
(Sully et al. 2019). Here, we show that resistance of corals to heat stress is geographically variable and likely driven by the differential environmental histories.

Resistance is a measure of system change when exposed to stress, and a key component of coral reef resilience or the ability of a reef to resist and survive a disturbance (McClanahan et al. 2012). Under the increasing impacts of climate change, coral bleaching is an early and obvious indicator of thermal stress (Hughes et al. 2018). Bleaching is less often considered for its potential to inform resistance, whereby some reefs may bleach less than expected based on historical and current environmental conditions or exposure to thermal stress (Fig. 1a). Ultimately, resistance should be influenced by variation in geographical and evolutionary history and associated genotypic diversity, adaptation to thermal stress, and taxonomic composition (Edmunds \& Gates 2008; Palumbi et al. 2014; Sully et al. 2019). These patterns remain untested across large biogeographic scales but will be critical for calibrating future climate impact models that are currently based on current and projected thermal exposure (Couce et al. 2013; Freeman et al. 2013; McManus et al. 2019).

Here, we combine satellite SST observations with a globally coordinated effort of coral bleaching surveys to evaluate coral resistance to heat stress across a large geographic gradient in 2016 (Fig. 1a). We evaluated resistance through two components: exposure to extreme heat stress and the resulting sensitivity of ecological communities to that exposure. We define exposure as the degree, duration, and extent of perturbations beyond background levels. As coral exposure to heat and light perturbations increases with climate change, reef resilience is threatened but also potentially attenuated by variable coral sensitivity and subsequent resistance (Sully et al. 2019). To evaluate coral reef exposure, we considered two models derived from NOAA AVHRR satellite measurements that provided proxies for a number of essential ocean variables that are used to estimate stress to corals (Eakin et al. 2010; Maina et al. 2008; 2011; Muller-Kager et al. 2018). We used two models: (1) a single metric of temperature stress - the cumulative incremental sum of SSTs above local summer SSTs (CTA), and (2) a multivariate metric of climate exposure (CE), which is a weighted index combining heat, light, and water flow variables and strongly associated with field observations of coral bleaching (Maina et al. 2008). Additionally, coral reef field biologists have developed field measurements to estimate coral bleaching and therefore ecological sensitivity. Sensitivity can take various forms, but here we define and document it as the percentage of corals that lost color, a proxy for the decline in light-absorbing algal symbiont densities, which can lead to coral mortality (Fitt et al. 2001; McClanahan et al. 2001).

\section{Materials and methods}

Resistance is a system-level metric used to estimate the balance between environmental exposure and biological sensitivity. There are a number of potential variables and ways to calculate it. Exposure and sensitivity can be measured by single or multiple variables, having different units, and often needs to be weighted, standardized, or normalized for appropriate comparisons. Moreover, resistance can be calculated as either the difference or ratio between exposure and sensitivity. Therefore, a number of these possibilities were evaluated and described below.

\section{Exposure}

We considered two exposure models, one based on a single variable of excess temperature exposure (cumulative degree heating weeks, the CTA model) and one based on a multivariate environmental index of climate exposure $(\mathrm{CE})$ that integrates temperature, winds and water flow into a weighted metric of exposure. The CTA model is based on the concept of cumulative degree heating weeks or months, or the amount of excess temperatures above a summer baseline, and is the most commonly used metric to assess the probability of coral bleaching and the future state of coral reefs (Eakin et al. 2010; van Hooidonk et al. 2013; Donner \& Carilli 2019). For each site, we extracted daily SST time series from the 5-km NOAA Coral Reef Watch version 3.1 products between 1985 and 2015, available from the NOAA website (https://coralreefwatch.noaa.gov/satellite/bleaching $5 \mathrm{~km} /$ index.php). Daily temperature measurements were used to calculate monthly hotspots, defined as positive SST anomalies referenced to the maximum of the monthly mean SST climatology (i.e. MMM climatology of Strong et al. 2004). We then calculated the 
Degree-Heating Months (DHM) as the sum of hotspots with monthly means [?] $0^{\circ} \mathrm{C}$. To derive the cumulative $\mathrm{DHM}$ product for each site, we summed cells with $\mathrm{DHM}>0^{\circ} \mathrm{C}$ for each year over the $1985-2015$ time series. We did not include the 2016 SST satellite measurements in this metric to maintain independence of the sensitivity metric established from underwater bleaching surveys during 2016. Cumulative thermal anomalies (CTA) between 1985-2015 ranged from 7.8 to 48.0 DHM across the 226 reef sites included in this study.

Climate Exposure $(\mathrm{CE})$ is a multivariate metric that combines radiation variables to optimize predictions for coral bleaching (Maina et al. 2008; 2011). The model was developed using variables derived from historical SST (mean, variability, maximum, minimum), ocean current velocity in zonal and meridional direction, wind velocity (number of doldrum days and wind speed magnitude), and average satellite derived UV and photosynthetic active radiation measurements. These measurements were synthesized using fuzzy logic and weighted based on bleaching observation to produce values ranging between 0 (least exposure) and 1 (highest exposure). Overall, this multivariate metric of coral exposure has a strong relationship to previous compilations of coral bleaching data (Maina et al. 2008). Comparing the two exposure models showed that the distributions of CTA and CE values for the 226 sites found the CTA means were more frequently clustered around lower values ( $<0.50$ normalized values) of the distribution and had a right skew. $\mathrm{CE}$ values were distributed more frequently towards the high ends ( $>0.50$ normalized values) and had a left skew (Supplementary Fig. 1).

\section{Sensitivity}

Field work to estimate coral ecological sensitivity were based on coordinated surveys of coral bleaching during the 2016 El Niño and global thermal anomaly event. All were undertaken after the post-peak summer SSTs when bleaching was greatest (McClanahan et al. 2001). We sampled the 226 sites in 12 countries between during summer months between March and September 2016. We used a roving observer methodology where an observer evaluates the frequency and severity of bleaching for individual coral colonies in a series of haphazardly replicated quadrats $\left(\sim 1.5 \mathrm{~m}^{2} \mathrm{x} \sim 15\right.$ replicates, across an area of $\left.\sim 1000 \mathrm{~m}^{2}\right)$. In some surveys, we photographed quadrats and subsequently identified colonies to taxa and scored them for bleaching. Within each quadrat, we identified hard coral colonies $>5 \mathrm{~cm}$ to genus (Veron 2000), and scored each colony for bleaching severity using the following categories: $c 0$-normal; $c 1$ - pale; $c 2-0-20 \%$ bleached; $c 3-21-50 \%$ bleached; $c 4-51-80 \%$ bleached, $c 5-81-100 \%$ bleached; $c 6$ - recently dead. These observations were used to estimate the average percent of bleaching coral colonies and a weighted measure of bleaching (McClanahan et al. 2007). We also recorded the site's depth, habitat type, and management. We also estimated hard coral cover in each quadrat to the nearest $5 \%$ and the summarized the number of observed colonies, coral taxa richness, and relative abundance for each site. Three sites were missing one of more of the variables leading to slightly lower sample sizes in some analyses.

\section{Data analyses}

Sensitivity was estimated in two ways, using both an unweighted and a weighted percentage of bleached corals. The unweighted method calculated the percentage of coral colonies that were pale to fully bleached as the percentage of all corals sampled. The weighted or bleaching intensity metric placed colonies into seven categories of bleaching ranging from normal to $100 \%$ bleached white and uses these categories to weight the responses of bleaching (McClanahan et al. 2007). Bleaching susceptibility is a related metric used to estimate the sensitivity of the community to bleaching, where the relative abundance of each taxa was multiplied by the mean bleaching intensity for that taxa based on either historical or recent observations and summed. Here, we used the 2016 bleaching intensity observations for each taxon. Bleaching susceptibility provides a single number for each site, where higher values indicate a coral assemblage with a higher susceptibility to bleaching and lower values indicate a coral assemblage that is less susceptible to bleaching. The two estimates were highly correlated $(\mathrm{r}=0.92, \mathrm{p}<0.0001)$.

The timing of the exposure (satellite temperature observations) and ecological sensitivity as percentage of bleached corals were evaluated for their predictive strength based on AIC values of relationships with 
predictor variables possible relationships before combining into a resistance metric. First, we extracted daily 5 -km SST time series for 90 days prior to field survey at each site and calculated the date of maximum observed DHMs. We found that all of the final 226 selected sites were sampled within 21 days after peak SSTs. Thereafter, we evaluated the two metrics of sensitivity (the unweighted percent bleaching and weighted bleaching intensity metrics) for their distributions, outliers, and associations with seven predictor variables. We found that 10 sites in Ningaloo reefs were outliers as per the multivariate Mahanalobis distance method. Exploration of these outliers suggest local oceanographic effects at Ningaloo were overriding the broaderscale satellite measurement values (Woo et al. 2006; Xu et al. 2016). Some error is expected in these analyses due to the scale mismatch of the satellite and field surveys, where field surveys are contained with satellite measurements dimensions but cover a smaller area. Nevertheless, we decided to retain these sites in all analysis as they represented some of this natural and scaler variability and possible influence on the models that we explored.

To evaluate resistance, we first normalized the exposure of the two metrics and the metric of ecological sensitivity selection for all sites between 0 and +1 , added +1 to all values and then divided exposure by sensitivity. These transformations eliminated zeroes and negative numbers and produced resistance values between 0.5 and 1.75 (Supplementary Fig. 1). Prior to calculating resistance, we evaluated statistical attributes of the single variables, interacting variable, and the ratio versus subtraction method to calculate resistance. Comparison of AIC values for bleaching versus the bleaching index against predictor variables indicated lower values for the percentage $(\mathrm{AIC}=125.7+97.1(+\mathrm{SD}) \mathrm{n}=28$ comparisons $)$ versus bleaching index $(\mathrm{AIC}=141.1+78.1, \mathrm{n}=28)$. Similarly, comparing the subtraction and the ratio method for estimating resistance found the ratios produced considerably lower AIC values (AIC $=62.8+56.6, \mathrm{n}=28$ ) than subtraction $(\mathrm{AIC}=204.1+46.1, \mathrm{n}=28)$.

Distributions of these chosen exposure, sensitivity, and the two metrics of resistance showed continuous distributions with weak centralization that should increase the probabilities of detecting patterns (Supplementary Fig. 1). Visualization of the scatterplot matrix of the 7 variables indicated that mean SST and kurtosis were strongly correlated $(\mathrm{r}=0.83)$ while all other variables correlations were $<0.56$. Therefore, we specified the model to not simultaneously include kurtosis and mean SST. Variance inflation scores - another indicator of multicollinearity - are presented for each top model and are all $<3$ (Table 1), indicating collinearity is not a serious concern. Sites were pooled into a general location for the analysis until the fit of a Generalized Linear Mixed Model (GLMM) with location as a random effect revealed nonuniformity and under-dispersion of the residuals. Consequently, location was removed from the final Generalized Linear Model (GLM) approach, and no spatial auto-correlation was found. Thereafter, we used a multi-model inference framework and fit the GLMs with the resistance ratio calculated from each of the two exposure models (CTA vs CE) against the 7 predictor variables with a Gaussian log-link error structure. All possible sub-models were computed using the dredge function from the MuMIn package in R. We present all the results of the top set models where delta AICc values $<2$ and where mean SST was excluded. This multi-model approach of evaluating all possible models reduces the changes of subjectively selecting significant but the not best models (Burnham and Anderson 1998).

We tested for difference in resistance, thermal environments, coral communities, and bleaching by major taxon for sites with all comparable variables within $(n=27)$ and outside the Coral Triangle $(n=199)$. Most data failed to pass tests of normality (using Kolmogorov-Smirnov-Lilliefors, KSL, tests) and therefore nonparametric Wilcoxon tests were undertaken for comparisons of all variables. Temperature data were pooled to visualize their distributions in the two regions. Coral communities were evaluated by multivariate Community Correspondence Analysis using the vegan package in R. The first and second values for each site were extracted and tested for differences between the two regions.

Both exposure and sensitivity metrics show good spread across the geographic coverage of this study (Supplementary Fig. 1). We then estimated resistance as exposure divided by sensitivity, and tested the hypotheses that resistance differed locally and geographically as influenced by biogeographical location, recent environmental forces over the past two decades, and attributes of the coral taxa and communities. We specifically 
evaluated whether the marine biodiversity center, known as the Coral Triangle (Spalding et al. 2007), had the same resistance and future prognosis as lower diversity peripheral reefs outside the Coral Triangle.

Previous studies have suggested that background SST mean and distribution (i.e. skewness and kurtosis) and its timing can influence bleaching and mortality by influencing coral acclimation and adaptation mechanisms (Ateweberhan and McClanahan 2010; Grottoli et al. 2014; Ainsworth et al. 2016; Langlais et al. 2017; Safaie et al. 2018). Temperature mean, skewness, and kurtosis describe the average and extreme temperature conditions, and can covary to inflate covariance in multivariate models. For example, kurtosis increases strongly and exponentially with increasing SSTs while skewness declines but is highly variable at high SSTs depending on the local geography. To avoid selectivity of model selection based on significance alone, we used a multi-model framework where all possible models were evaluated and compared (Burnham and Anderson 1998). Multicollinearity was evaluated and temperature metrics with high correlations were included separately when exploring the strength of 128 model combinations. To account for non-random sampling, we included the geographic variables of longitude and latitude in addition to SST variables of mean, kurtosis, and skewness, and coral community variables comprising hard coral cover and genera richness. Sampling of longitude and latitude was not random and therefore evaluated as fixed covariates in models.

\section{Results}

We found that resistance varied unevenly across our study sites with lowest resistance in the northern and western Indian Ocean (Fig. 1b,c). The highest resistance was observed in the equatorial Coral Triangle and intermediate resistance south of the equator and some sites, such as Ningaloo reef. For resistance estimated by CTA, there were two best models that contained 5 and 6 of the 7 variables. The first top model excluded coral cover and kurtosis while the second top model excluded only kurtosis (Table 1). The $9^{\text {th }}$ ranked model, where mean SST was excluded,. included the three variables of longitude, number of genera, and skewness. The multivariate exposure model (CE) had only one top model and only kurtosis was excluded. Excluding mean SST produced the $3^{\text {rd }}$ ranked model, which included all variables including kurtosis. The CTA model had somewhat higher strengths than the resistance models estimated from the CE $\left(\mathrm{CTA} \mathrm{R} \mathrm{R}^{2}=0.82\right.$ versus $\mathrm{CE}$ $\mathrm{R}^{2}=0.72$ ). Both models displayed separation in responses between Coral Triangle and non-Coral Triangle sites but differences were more evident in the CTA model. The CTA method estimated $62 \%$ and CE $38 \%$ higher resistance in Coral Triangle than non-Triangle sites (Table 2, Fig. 2). Consequently, the higher fits to the CTA and CE model was likely due to the greater separation and influences of CTAs on resistance in Coral Triangle versus non-Triangle sites. While most variables were included in top models, there were marked differences in the strengths of the variables and their order among different model combinations. Longitude, number of genera, mean SST, and kurtosis were positively while SST skewness and latitude negatively associated with resistance. Hard coral was, however, weak and complex in that the direction of the association with resistance differed for the exposure models, positive for CTA and negative for CE.

Geography played a significant role in affecting resistance in nearly all models, but it also interacted with SST and number of coral taxa patterns. Comparisons of the Coral Triangle and non-Coral Triangle sites illuminated some associations in the two distinct patterns of SST, coral communities, and resistance (Table 2, Fig. 3). Pooling and evaluating the SST time series indicated considerable differences between regions in exposure. The higher CTA in the Coral Triangle was one of the most pronounced difference with 2.5 times more 1985-2015 CTAs than non-Triangle sites. Moreover, Coral Triangle sites had warmer SSTs, more neutral kurtosis, and negative or cold-water skewness compared to non-Triangle sites (Fig. 3). In fact, distinct differences in the skewness-kurtosis associations was one of the main geographic distinctions. Coral Triangle sites had only neutral to high SST kurtosis and, as kurtosis increased, skewness declined and was negative. Kurtosis was highly variable in non- Triangle sites but warm-water skewness increased when kurtosis was high.

Differences in resistance between Coral Triangle and non-Triangle sites cannot be attributable to differences in the coral communities. We found that coral cover, the relative taxonomic composition and the community's susceptibility to bleaching did not differ between geographies (Table 2, Fig. 4). What did consistently differ was the percentage of bleached corals, the weighted and unweighted bleaching responses and the percentage 
of the dominant taxa that were bleached in 2016. All metrics showed higher bleaching outside the Coral Triangle despite lower mean historical SSTs and CTAs.

\section{Discussion}

Mean SSTs, rates of temperature rise, and CTAs are the key metrics used to model current and future impacts and refuge from climate change (Hoegh-Guldberg 1990; van Hooidonk et al., 2013, 2016; Beyer et al. 2018). Use of these and related thermal metrics produce dire predictions for corals, especially in warm equatorial regions such as the Coral Triangle (Couce et al. 2013; McManus et al. 2019). Yet, the large-scale differences observed here were largely attributable to the variable responses of coals to exposure and their differential spatial acclimation/adaptation at the taxa level. There were enough similarities in communities among the studied sites that observed differences were most likely due to similar taxa having different resistance levels (Fig 4). Thus, resistance appears to have a strong component of regionalism that is not clearly related to differences in coral species composition.

The Coral Triangle appears to have a unique temperature environment and harbor corals with greater resistance to exposure. Historically, the Coral Triangle has been influenced by oceanographic processes, such as El Niño Southern Oscillation (ENSO). The strengths of the ENSO have long fluctuated longitudinally across the Pacific for millennium and most be part of the adaptive environment experience by Coral Triangle corals (Cobb et al. 2003). Our findings suggest that ENSO variation and inter-annual warm thermal anomalies in the western Pacific were primary drivers of coral resistance along the east-west gradient from East Africa to Fiji. Moreover, resistance is higher but unequally distributed closer to the equator, which indicates that exposures to thermal radiation alone cannot explain variability. Variation in resistance close to the equator may explain the overall higher bleaching reported in mid-tropical latitudes $\left(15-20^{\circ}\right)$ despite equal or higher CTA near the equator (Sully et al. 2019). Some variation in bleaching variation was attributable to average background SST variation but we found that shape parameters of kurtosis and particularly skewness were more likely to distinguish sites along this equatorial belt.

The Coral Triangle differs in having negative skewness and neutral to high kurtosis, which are associated with increased resistance. The causes of the negative skewness require more investigation but it likely that the island nature of the Coral Triangle creates localized variability in water clarity, ocean currents and up- and downwelling that may provide some localized variation in radiation, temperatures, productivity, and resistance (McClanahan et al. 2005; Gove et al. 2016). Statistical outlier sites at Ningaloo retained in our analysis may provide some insight by being an exception to the Coral-non-Coral Tringle and midlatitude patterns. We suggest that the higher than expected resistance found in Ningaloo arose from localized upwelling, onshore geostrophic transport, and stirring by offshore eddies that produced lower than expected bleaching (Xu et al. 2016). Satellite measurements even at $5 \mathrm{~km}^{2}$ may not capture these local processes well (Woo et al. 2006; Wilson, S. personal communication). It should be appreciated that there is a scale mismatch between exposure and bleaching observations, a problem that troubles most ground-truthing studies, and can results in errors and some anomalous observations that can weaken predictions.

Differences in SST distributions have produced similar patterns in other studies. For example, change in coral cover over the 1998 bleaching event was influenced by SST variation and distribution shapes - heavy-tailed distributions associated with higher coral mortality (Ateweberhan \& McClanahan 2010). Further, in a largescale study of coral cover and community composition in western Australian, SST kurtosis and skewness were frequently among the top variables for predicting coral abundance (Zinke et al. 2018). Skewed right SST distributions were, for example, associated with lower cover of stress-resistant corals. Additionally, positive kurtosis, or heavy-tailed distributions, was associated with lower cover of all corals. Both of these distribution shape variables would be expected to influence coral acclimation processes. On the basin scale of the Indian Ocean, coral taxonomic richness was found to be positively influenced by mean and negatively by heavytailed SST distributions (Ateweberhan et al. 2018). Consequently, background SSTs have repeatedly been shown to influence sensitivity and resistance and differ most clearly in the complex relationships between mean variance, kurtosis, and skewness. Thus, the mean SSTs-bleaching association (Claar et al. 2018; Sully et al. 2019) has the potential to be modified by other background SST distribution factors and not just mean 
variance (Langlais et al. 2017; Safaie et al. 2018). For example, we found that the potentially negative effects of positive kurtosis, which is expected to reduce predictable SST variation and acclimation in corals, may not be detrimental when temperatures profiles lack positive skewness. Thus, their interaction in space and time may prove useful in exposing some of the complexities of stress and coral responses.

Coral community variables had statistically significant influence on resistance, particularly when mean SST was eliminated from the predictive variables. Coral cover-resistance relationships were complex due to the change in direction of this variable for the two exposure models. Number of genera was, however, consistently positively related to resistance and particularly in the absence of mean SSTs. Consequently, mean SST may influence coral richness as found in other geographic studies but it is not clear which of these variables is driving the response to exposures. Given that mean SST and geography could be proxies rather than physical or ecological driver of resistance, number of taxa could be a modest driver of resistance given the expected diversity-portfolio responses (Cardinale et al. 2012; Schindler et al. 2015). Distinguishing cause and effect between these variables and associations with resistance is a priority area for future research.

Measuring future resistance in corals will depend on the effectiveness of exposure and sensitivity to reflect stresses and responses that will vary over time. Changes and increasing ocean heat forced by climate change means that exposure and sensitivity could change and potentially decouple in the future. Moreover, there is the question of how good bleaching is at measuring sensitivity to thermal stress (Buddemeier et al. 2004). Bleaching is potentially one of a number of possible adaptive responses to heat or climate warming stress. Mortality without bleaching, for example, is an infrequently examined response that could influence resistance estimates (McClanahan 2004). Differential rates and clearly identified causes of mortality and recovery among taxa creates challenges for large-scale evaluations of climate impacts (McClanahan et al. 2001; Darling et al. 2019). Estimating mortality requires inter-annual monitoring to evaluate changes that could be poorly tied to heat stress alone (Darling et al. 2013; Donner \& Carilli 2019). While we acknowledge this weakness, bleaching is currently the most commonly used and quantifiable way to measure sensitivity to heat stress (Donner et al. 2017; Sully et al. 2019).

Difference between the two exposure models contributes to understanding the geography of environmental stress in the tropics. The propagation of east-west inter-annual SST variability driven by the ENSO is a critical exposure force. Longitudinal propagation of exposure can explain the uneven distribution of CTAs, differences between the two exposure models, and the separation of the Coral from non-Triangle sites. ENSO is likely to be the dominant force over historical time, controlling reef development in the eastern Pacific and recently increasing in strength in the western Pacific (Peñaflor et al. 2009; Toth et al. 2015). The increasing strength of the ENSO has also been associated with increases in the penetration of warm waters into the eastern Indian Ocean (Zinke et al. 2015). Additionally, the Indian Ocean Dipole has been increasing in strength since the 1920s and adding to the ENSO heat stress (Nakamura et al. 2009; McClanahan 2017). Consequently, the more recent origins of these forces in the Indian Ocean, may explain the higher sensitivity and lower resistance of corals observed here.

The higher resistance of corals in the western Pacific or Indo-Pacific biodiversity center indicates geographic variability that reflects shallow-water biodiversity patterns (Veron et al. 2011; Parravicini et al. 2013). The Coral Triangle has a spatially variable SST environment (Peñaflor et al. 2009; McLeod et al. 2010) but we found a combination of high anomalies, neutral to cold-SST skew, and neutral kurtosis. We suggest that these heat patterns provided some resistance to episodic strong thermal disturbances. High biodiversity in the Coral Triangle has arisen from a number of interacting forces that are likely to include environmental as well as geologic complexity, isolation, and changing sea level forces (Barber \& Meyer 2015).

Our findings support the contention that historical forces may also be associated with a higher capacity to tolerate episodic large-scale global heat stress, as observed during this pan-tropical thermal stress event of 2014-2016. Many models that predict the future of coral reefs treat CTAs, bleaching, and mortality as interchangeable. Yet, we show here that sensitivity is highly variable and contextual. Therefore, better predictions for the future state of coral reefs should use resistance metrics rather than just the initial and projected exposure metrics. Greater resistance to thermal stress in the Coral Triangle may delay and attenu- 
ate the observed increases in warm-water stress responses (Hughes et al. 2018). Thus, our findings indicate a limited window of opportunity to better manage the impacts and produce less severe outcomes in the Coral Triangle. Nevertheless, reducing heat-retaining gas emissions, developing sustainable fisheries, and improving watershed and pollution management remain priorities for coral persistence.

\section{ACKNOWLEDGEMENTS}

TRM and NAM received support from the John D. and Catherine T. MacArthur Foundation and the Sustainable Poverty Alleviation from Coastal Ecosystem Services (SPACES) NE-K010484-1 project. ESD was supported by a Banting Postdoctoral Fellowship from the Natural Sciences and Engineering Research Council of Canada, and the John D. and Catherine T. MacArthur Foundation. Data collection in the Solomon Islands was supported by the Wallace Research Foundation, and by the Waitt Foundation in Fiji. Maldives data collection was supported by IUCN and USAID. MMMG received support from the French National Research Agency under the STORISK project (No. ANR-15-CE03-0003). Data collection in Zanzibar was partly supported by NORHED project coordinated by the State University of Zanzibar (SUZA). The Tiffany \& Co. Foundation and the John D. and Catherine T. MacArthur Foundation supported data collection in some Western Indian Ocean reefs. VJP received support from the DST-INSPIRE Faculty Programme, and Z. Tyabji \& S. Chandrasekhar assisted VJP with data collection in the Andaman Islands. RA received funding support from the Rohini Nilekani Philanthropies and an Intramural Project from the Spanish National Research Council (CSIC-201330E062). SAK was funded by the VILLUM Foundation (No.10114). ATH received funding from the Carnegie Corporation of New York. Indonesia data collection was supported by the John D. and Catherine T. MacArthur Foundation and Margaret A. Cargill Philanthropies. We greatly thank the following people for assistance with data collection: A. Baird, A. Halford, S. Keith, R. J.-L. Komeno, C. Miternique, A. dan Muhidin, E. Muttaqin, E. Montocchio, C. Muhando, Y. Nand, S. Pardede, N. Summers, and S. Yadav.

\section{REFERENCES}

1. Ainsworth, T.D.A., Heron, S.F., Ortiz, J.C., Mumby, P.J., Grech, A., Ogawa, D. et al. (2016). Climate change disables coral bleaching protection on the Great Barrier Reef. Science, 352, 338-342.

2. Ateweberhan, M. \& McClanahan, T.R. (2010). Relationship between historical sea-surface temperature variability and climate change-induced coral mortality in the western Indian Ocean. Marine Pollution Bulletin , 60, 964-970.

3. Ateweberhan, M., McClanahan, T.R., Maina, J. \& Sheppard, C. (2018). Thermal energy and stress properties as the main drivers of regional distribution of coral species richness in the Indian Ocean. Journal of Biogeography , 45, 1355-1366.

4. Barber, P.H. \& Meyer, C.P. (2015). 30 Pluralism explains diversity in the Coral Triangle . Cambridge University Press, United Kingdom.

5. Beyer, H.L., Kennedy, E.V., Beger, M., Chen, C.A., Cinner, J.E., Darling, E.S. et al. (2018). Risk-sensitive planning for conserving coral reefs under rapid climate change. Conservation Letters, 11, e12587.

6. Boulotte, N.M., Dalton, S.J., Carroll, A.G., Harrison, P.L., Putnam, H.M., Peplow, L.M. et al. (2016). Exploring the Symbiodinium rare biosphere provides evidence for symbiont switching in reef-building corals. The ISME Journal , 10, 2693.

7. Buddemeier, R.W., Baker, A.C., Fautin, D.G. \& Jacobs, J.R. (2004). The adaptive hypothesis of bleaching. In: Coral Health and Disease (eds. Rosenberg, E \& Loya, Y). Springer Berlin Heidelberg, pp. 427-444.

8. Burnham, K.P. \& Anderson, D.R. (1998). Model Selection and Multimodel Inference: A Practical Information-theoretic approach . 2nd ed edn. Springer, New York. 
9. Cardinale, B.J., Duffy, J.E., Gonzalez, A., Hooper, D.U., Perrings, C., Venail, P. et al. (2012). Biodiversity loss and its impact on humanity. Nature, 486, 59-67.

10. Claar, D.C., Szostek, L., McDevitt-Irwin, J.M., Schanze, J.J. \& Baum, J.K. (2018). Global patterns and impacts of El Nino events on coral reefs: A meta-analysis. PLoS One, 13, e0190957.

11. Cobb, K.M., Charles, C.D., Cheng, H. \& Edwards, R.L. (2003). EI Nino/Southern Oscillation and tropical Pacific climate during the last millennium. Nature , 424, $271-276$.

12. Couce, E., Ridgwell, A. \& Hendy, E.J. (2013). Future habitat suitability for coral reef ecosystems under global warming and ocean acidification. Global change biology , 19, 3592-3606.

13. Darling, E.S., McClanahan, T.R. \& Cote, I.M. (2013). Life histories predict coral community disassembly under multiple stressors. Global Change Biology , 19, 1930-1940.

14. Darling, E.S., McClanahan, T.R., Maina, J., Gurney, G.G., Graham, N.A., Januchowski-Hartley, F. et al. (2019). Social-environmental drivers inform strategic management of coral reefs in the Anthropocene. Nature Ecology $\&$ Evolution, 3, 1341-1350.

15. Donner, S.D. \& Carilli, J. (2019). Resilience of Central Pacific reefs subject to frequent heat stress and human disturbance.Scientific Reports , 9, 1 - 13.

16. Donner, S.D., Rickbeil, G.J. \& Heron, S.F. (2017). A new, high-resolution global mass coral bleaching database. PLos One, 12, e0175490.

17. Eakin, C.M., Morgan, J.A., Heron, S.F., Smith, T.B., Liu, G., Alvarez-Filip, L. et al. (2010). Caribbean corals in crisis: Record thermal stress, bleaching, and mortality in 2005. PLoS One, 5, e13969.

18. Edmunds, P.J. \& Gates, R.D. (2008). Acclimatization in tropical reef corals. Mar. Ecol. Prog. Ser. , $361,307-310$.

19. Fitt, W.K., Brown, B.E., Warner, M.E. \& Dunne, R.P. (2001). Coral bleaching: Interpretation of thermal tolerance limits and thermal thresholds in tropical corals. Coral Reefs , 20, 51-65.

20. Freeman, L.A., Kleypas, J.A. \& Miller, A.J. (2013). Coral reef habitat response to climate change scenarios. PLoS One, 8, e82404.

21. Gove, J.M., McManus, M.A., Neuheimer, A.B., Polovina, J.J., Drazen, J.C., Smith, C.R. et al. (2016). Near-island biological hotspots in barren ocean basins. Nature Communications, 7.

22. Grottoli, A.G., Warner, M.E., Levas, S.J., Aschaffenburg, M.D., Schoepf, V., McGinley, M. et al. (2014). The cumulative impact of annual coral bleaching can turn some coral species winners into losers. Global Change Biology , 20, 3823-3833.

23. Guest, J.R., Baird, A.H., Maynard, J.A., Muttaqin, E., Edwards, A.J., Campbell, S.J. et al. (2012). Contrasting patterns of coral bleaching susceptibility in 2010 suggest an adaptive response to thermal stress. PLoS One, 7, e33353.

24. Hoegh-Guldberg, O. (1999). Climate change, coral bleaching and the future of the world's coral reefs. Marine and Freshwater Research, 50, 839-866.

25. Hughes, T.P., Anderson, K.D., Connolly, S.R., Heron, S.F., Kerry, J.T., Lough, J.M. et al. (2018). Spatial and temporal patterns of mass bleaching of corals in the Anthropocene. Science, 359, 80-83.

26. Hughes, T.P., Barnes, M.L., Bellwood, D.R., Cinner, J.E., Cumming, G.S., Jackson, J.B. et al. (2017). Coral reefs in the Anthropocene. Nature, 546, 82-90.

27. Hughes, T.P., Kerry, J.T., Connolly, S.R., Baird, A.H., Eakin, C.M., Heron, S.F. et al. (2019). Ecological memory modifies the cumulative impact of recurrent climate extremes. Nature Climate Change, 9, 40-43. 
28. Langlais, C.E., Lenton, A., Heron, S.F., Evenhuis, C., Gupta, A.S., Brown, J.N. et al. (2017). Coral bleaching pathways under the control of regional temperature variability. Nature Climate Change , 7, 839844.

29. Maina, J., McClanahan, T.R., Venus, V., Ateweberhan, M. \& Madin, J. (2011). Global gradients of coral exposure to environmental stresses and implications for local management. PLoS One, 6, e23064.

30. Maina, J., Venus, V., McClanahan, T.R. \& Ateweberhan, M. (2008). Modelling susceptibility of coral reefs to environmental stress using remote sensing data and GIS models in the western Indian Ocean.Ecol. Mod. , 212, 180-199.

31. McClanahan, T.R. (2004). The relationship between bleaching and mortality of common corals. Mar Biol , 144, 1239-1245.

32. McClanahan, T.R. (2017). Changes in coral sensitivity to thermal anomalies. Mar. Ecol. Prog. Ser. , $570,71-85$.

33. McClanahan, T.R., Ateweberhan, M., Graham, N.A.J., Wilson, S.K., Sebastian, C.R., Guillaume, M.M. et al. (2007). Western Indian Ocean coral communities: Bleaching responses and susceptibility to extinction. Mar. Ecol. Prog. Ser. , 337, 1-13.

34. McClanahan, T.R., Baker, A.C., Ateweberhan, M., Maina, J. \& Moothien-Pillay, K.R. (2005). Refining coral bleaching experiments and models through reiterative field studies. Mar. Ecol. Prog. Ser. , 305, 301-303.

35. McClanahan, T.R., Donner, S.D., Maynard, J.A., MacNeil, M.A., Graham, N.A., Maina, J. et al. (2012). Prioritizing key resilience indicators to support coral reef management in a changing climate. PLoS One, 7, e42884.

36. McClanahan, T.R., Muthiga, N.A. \& Mangi, S. (2001). Coral and algal changes after the 1998 coral bleaching: Interaction with reef management and herbivores on Kenyan reefs. Coral Reefs , 19, 380-391.

37. McLeod, E., Moffitt, R., Timmermann, A., Salm, R., Menviel, L., Palmer, M.J. et al. (2010). Warming seas in the coral triangle: Coral reef vulnerability and management implications. Coastal Management, 38, 518-539.

38. McManus, L.C., Vasconcelos, V.V., Levin, S.A., Thompson, D.M., Kleypas, J.A., Castruccio, F.S. et al. (2019). Extreme temperature events will drive coral decline in the Coral Triangle. Global Change Biology .

39. McManus, L.C., Vasconcelos, V.V., Levin, S.A., Thompson, D.M., Kleypas, J.A., Castruccio, F.S. et al. (2019). Extreme temperature events will drive coral decline in the Coral Triangle. Global Change Biology .

40. Muller-Karger, F.E., Miloslavich, P., Bax, N.J., Simmons, S., Costello, M.J., Sousa Pinto, I. et al. (2018). Advancing marine biological observations and data requirements of the complementary essential ocean variables (EOVs) and essential biodiversity variables (EBVs) frameworks. Frontiers in Marine Science $, 5,211$.

41. Nakamura, N., Kayanne, H., Iijima, H., McClanahan, T.R., Behera, S.K. \& Yamagata, T. (2009). Mode shift in the Indian Ocean climate under global warming stress. Geophysical Research Letters , 36, Doi:10.1029/2009GL040590, 042009.

42. Palumbi, S.R., Barshis, D.J., Traylor-Knowles, N. \& Bay, R.A. (2014). Mechanisms of reef coral resistance to future climate change.Science, 344, 895-898.

43. Parravicini, V., Kulbicki, M., Bellwood, D.R., Friedlander, A.M., Arias-Gonzalez, J.E., Chabanet, P. et al. (2013). Global patterns and predictors of tropical reef fish species richness. Ecography, 36, 1254-1262.

44. Penaflor, E.L., Skirving, W.J., Strong, A.E., Heron, S.F. \& David, L.T. (2009). Sea-surface temperature and thermal stress in the Coral Triangle over the past two decades. Coral Reefs , 28, 841-850. 
45. Safaie, A., Silbiger, N.J., McClanahan, T.R., Pawlak, G., Barshis, D.J., Hench, J.L. et al. (2018). Author Correction: High frequency temperature variability reduces the risk of coral bleaching. Nature Communications , 9, 2244.

46. Schindler, D.E., Armstrong, J.B. \& Reed, T.E. (2015). The portfolio concept in ecology and evolution. Frontiers in Ecology and the Environment , 13, 257-263.

47. Spalding, M.D., Fox, H.E., Allen, G.R., Davidson, N., Ferdana, Z.A., Finlayson, M.A.X. et al. (2007). Marine ecoregions of the world: A bioregionalization of coastal and shelf areas. BioScience, 57, 573-583.

48. Strong, A.E., Liu, G., Meyer, J., Hendee, J.C. \& Sasko, D. (2004). Coral reef Watch 2002. Bulletin of Marine Science, 75, 259-268.

49. Sully, S., Burkepile, D.E., Donovan, M.K., Hodgson, G. \& van Woesik, R. (2019). A global analysis of coral bleaching over the past two decades. Nature Communications , 10, 1-5.

50. Toth, L.T., Aronson, R.B., Cheng, H. \& Edwards, R.L. (2015). Holocene variability in the intensity of wind-gap upwelling in the tropical eastern Pacific. Paleoceanography and Paleoclimatology, 30, 1113-1131.

51. Van Hooidonk, R., Maynard, J., Tamelander, J., Gove, J., Ahmadia, G., Raymundo, L. et al. (2016). Local-scale projections of coral reef futures and implications of the Paris Agreement. Scientific Reports , 6, 39666.

52. Van Hooidonk, R., Maynard, J.A. \& Planes, S. (2013). Temporary refugia for coral reefs in a warming world. Nature Climate Change , 3, 508 - 511.

53. Veron, J.C.E., DeVantier, L.M., Turak, E., Green, A.L., Kininmonth, S., Stafford-Smith, M. et al. (2011). The coral triangle. In:Coral reefs: An ecosystem in transition . Springer, Dordrecht Dordrecht, pp. $47-55$.

54. Veron, J.E.N. (2000). Corals of the World, Vol 1-3 . Australian Institute of Marine Science, Townsville, Australia.

55. Woo, M., Pattiaratchi, C. \& Schroeder, W. (2006). Dynamics of the Ningaloo current off point Cloates, Western Australia. Marine and Freshwater Research , 57, 291-301.

56. Xu, J., Lowe, R.J., Ivey, G.N., Jones, N.L. \& Zhang, Z. (2016). Ocean transport pathways to a world heritage fringing coral reef: Ningaloo Reef, Western Australia. PLoS One, 11, e0145822.

57. Zinke, J., Gilmour, J.P., Fisher, R., Puotinen, M., Maina, J., Darling, E. et al. (2018). Gradients of disturbance and environmental conditions shape coral community structure for south-eastern Indian Ocean reefs. Diversity and Distributions , 24, 605 - 620.

58. Zinke, J., Hoell, A., Lough, J., Feng, M., Kuret, A., Clarke, H.et al. (2015). Coral record of southeast Indian Ocean marine heatwaves with intensified Western Pacific temperature gradient.Nature Communications $, 6,8562$.

\section{Tables}

Table 1. Results and ranks of multi-model inference statistics . Ranks and fit of model outputs results of the best models of 96 options where 7 predictors were tested for associations with two resistance metrics at the study sites. For comparison, results of the single factors and the direction of influence used in the best models are included. Ranks are based on AIC criteria. NS $=$ not significant, ${ }^{*}=\mathrm{p}<0.05,{ }^{* *}=$ $\mathrm{p}<0.01$. Based on 204 sites because some sites lacked coral cover estimates.

\section{a) Resistance (cumulative thermal anomaly, CTA)}

Rank Models

Set 1: Best models set $(<2$ AICc) 


\begin{tabular}{ll}
\hline Rank & Models \\
\hline 1 & Resistance (CE) Intercept + Absolute latitude + Hard coral, \% + Longitude + No of gen \\
3 & Set 1b: Best model without SST \\
Set 2: Single variable models & Resistance (CE) Intercept + Absolute latitude + Hard coral, \% + Kurtosis + Longitude - \\
Rank & Models \\
69 & Longitude (+) \\
78 & Skewness (-) \\
87 & Absolute latitude (-) \\
90 & No of genera $(+)$ \\
92 & SST (+) \\
93 & Kurtosis $(+)$ \\
95 & Hard coral, \% (-) \\
\hline
\end{tabular}

\section{b) Resistance (Climate exposure, CE)}

Table 2. Regional comparisons of temperature, coral community, and dominant taxa. Longterm temperature metrics (mean, kurtosis and skewness) for sites within the coral triangle $(\mathrm{n}=27)$ and sites outside the coral triangle $(n=199)$ compared by the Wilcoxon tests of significance. Metrics of the coral communities and two measures of their bleaching responses. Community axis 1 and 2 are the first and second Community Correspondence Axes of a multivariate evaluation of coral taxa. Susceptibility weights taxa abundance by a mean bleaching response during the 2016 period. Bleaching intensity weights bleaching by 7 categories of bleaching intensity. DHM = degree heating months from 1985 to 2015. CTA = cumulative thermal anomaly model based on sum of DHM. CE = climate exposure model based on multiple environmental variables.

\begin{tabular}{|c|c|c|c|c|}
\hline Variable & $\begin{array}{l}\text { Coral triangle mean } \\
\text { (SD) }\end{array}$ & $\begin{array}{l}\text { Non-coral triangle } \\
\text { mean (SD) }\end{array}$ & $\mathrm{Z}$ & Prob $>|\mathrm{Z}|$ \\
\hline $\begin{array}{l}\text { Resistance } \\
\text { variables }\end{array}$ & $\begin{array}{l}\text { Resistance } \\
\text { variables }\end{array}$ & $\begin{array}{l}\text { Resistance } \\
\text { variables }\end{array}$ & $\begin{array}{l}\text { Resistance } \\
\text { variables }\end{array}$ & $\begin{array}{l}\text { Resistance } \\
\text { variables }\end{array}$ \\
\hline Resistance, CTA & $1.38(0.23)$ & $0.83(0.22)$ & 7.5 & $<.0001$ \\
\hline Resistance, CE & $1.42(0.27)$ & $1.03(0.26)$ & 5.7 & $<.0001$ \\
\hline $\begin{array}{l}\text { Temperature } \\
\text { variables }\end{array}$ & $\begin{array}{l}\text { Temperature } \\
\text { variables }\end{array}$ & $\begin{array}{l}\text { Temperature } \\
\text { variables }\end{array}$ & $\begin{array}{l}\text { Temperature } \\
\text { variables }\end{array}$ & $\begin{array}{l}\text { Temperature } \\
\text { variables }\end{array}$ \\
\hline $\begin{array}{l}\text { Mean sea-surface } \\
\text { temperature }\end{array}$ & $28.93(0.44)$ & $27.57(1.16)$ & 6.3 & $<.0001$ \\
\hline Kurtosis & $0.05(0.31)$ & $-0.70(0.49)$ & 6.3 & $<.0001$ \\
\hline Skewness & $-0.48(0.19)$ & $0.03(0.27)$ & -7.3 & $<.0001$ \\
\hline Cumulative DHM & $43.10(4.30)$ & $18.80(7.40)$ & 8.3 & $<.0001$ \\
\hline $\begin{array}{l}\text { Coral community } \\
\text { variables }\end{array}$ & $\begin{array}{l}\text { Coral community } \\
\text { variables }\end{array}$ & $\begin{array}{l}\text { Coral community } \\
\text { variables }\end{array}$ & $\begin{array}{l}\text { Coral community } \\
\text { variables }\end{array}$ & $\begin{array}{l}\text { Coral community } \\
\text { variables }\end{array}$ \\
\hline $\begin{array}{l}\text { Hard coral cover, } \\
\%\end{array}$ & $43.65(21.59)$ & $43.75(21.64)$ & 0.2 & NS \\
\hline $\begin{array}{l}\text { Number of coral } \\
\text { taxa }\end{array}$ & $21.26(5.78)$ & $18.18(7.16)$ & 2.5 & 0.01 \\
\hline $\begin{array}{l}\text { Community Axis } \\
1\end{array}$ & $-0.11(0.78)$ & $0.02(0.76)$ & -1.0 & NS \\
\hline $\begin{array}{l}\text { Community Axis } \\
2\end{array}$ & $-0.17(0.39)$ & $0.02(0.74)$ & -0.4 & NS \\
\hline
\end{tabular}




\begin{tabular}{|c|c|c|c|c|}
\hline Variable & $\begin{array}{l}\text { Coral triangle mean } \\
\text { (SD) }\end{array}$ & $\begin{array}{l}\text { Non-coral triangle } \\
\text { mean }(\mathrm{SD})\end{array}$ & $\mathrm{Z}$ & Prob $>|\mathrm{Z}|$ \\
\hline $\begin{array}{l}\text { Community } \\
\text { bleaching } \\
\text { susceptibility, \% }\end{array}$ & $27.34(2.69)$ & $27.98(2.43)$ & -1.4 & NS \\
\hline Coral bleaching & Coral bleaching & Coral bleaching & Coral bleaching & Coral bleaching \\
\hline $\begin{array}{l}\text { Bleached colonies, } \\
\%\end{array}$ & $39.78(25.11)$ & $59.71(28.60)$ & -3.4 & 0.0007 \\
\hline $\begin{array}{l}\text { Bleaching } \\
\text { intensity, \% }\end{array}$ & $15.20(13.13)$ & $28.19(17.13)$ & -3.6 & 0.0003 \\
\hline Acropora, \% & $43.33(30.03)$ & $60.86(34.36)$ & -2.7 & 0.008 \\
\hline Montipora, \% & $32.85(24.31)$ & $59.98(40.17)$ & -2.8 & 0.005 \\
\hline Pocillopora, \% & $59.32(35.88)$ & $71.62(36.29)$ & -1.9 & 0.05 \\
\hline $\begin{array}{l}\text { Porites } \\
\text { branching, } \%\end{array}$ & $19.38(29.48)$ & $54.12(38.41)$ & -3.6 & 0.0003 \\
\hline $\begin{array}{l}\text { Porites massive, } \\
\%\end{array}$ & $26.36(27.65)$ & $53.84(34.44)$ & -3.8 & 0.0002 \\
\hline
\end{tabular}

Figures 
a)

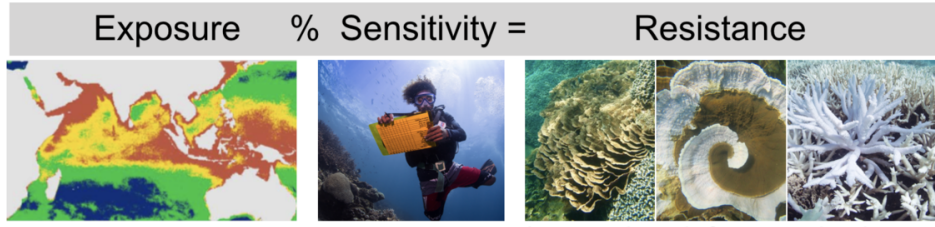

Global climate models:

1. Cumulative thermal

anomaly (CTA)

Coordinated coral bleaching

Integrated metric for measuring the

2. Climate exposure (CE) field surveys

- Higher resistance indicates systems

where sensitivity < exposure

- Lower resistance indicates reefs where sensitivity > exposure
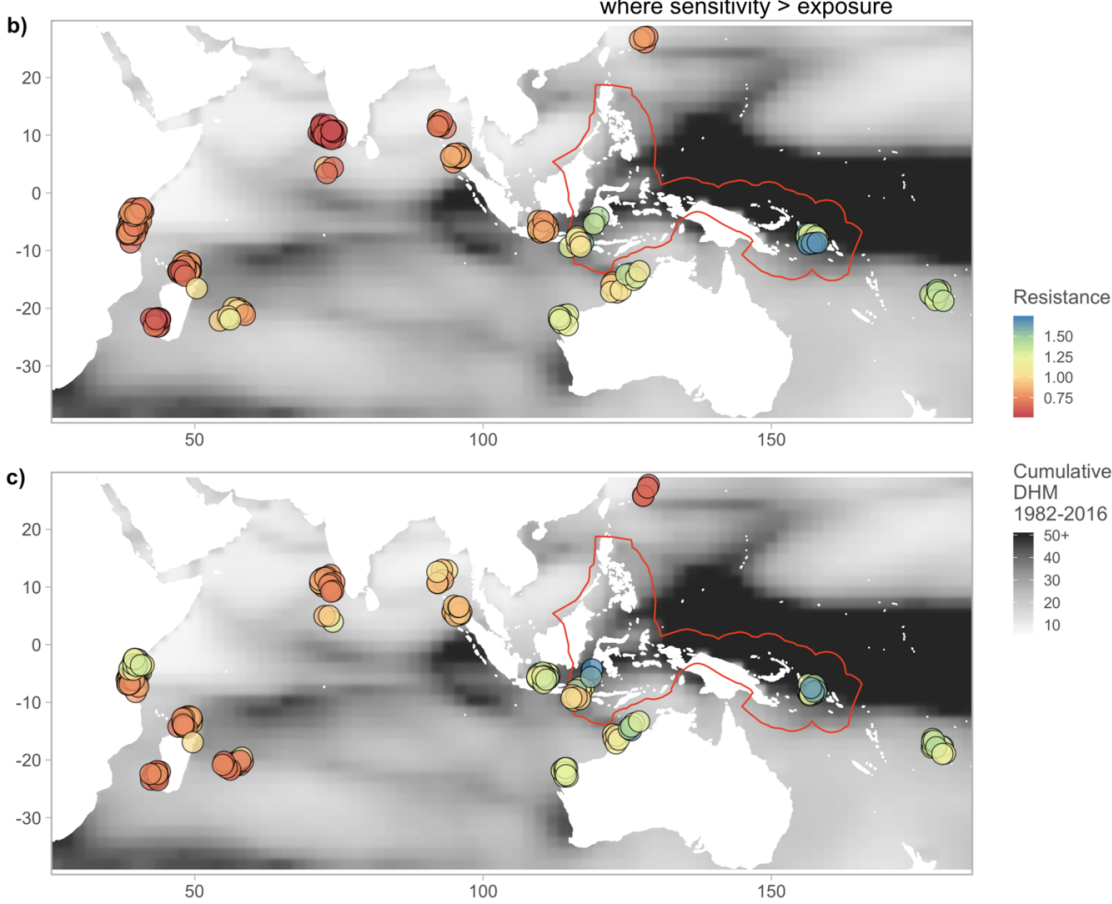

Figure 1. Evaluating coral reef resistance to the $2016 \mathrm{El}$ Niño thermal anomaly . (a) Resistance is a metric for measuring the capacity of coral reefs to resist bleaching, estimated from exposure to environmental stress divided by ecological sensitivity. (b) Map of 226 Indo-Pacific coral reefs showing resistance calculated using a cumulative thermal anomaly (CTA) exposure model and (c) using a multivariate climate exposure (CE) model. Coloured dots show resistance; background shading represents chronic heat stress, evaluated as cumulative degree heating months (DHM) between 1982 and 2016 estimated from satellite data. 

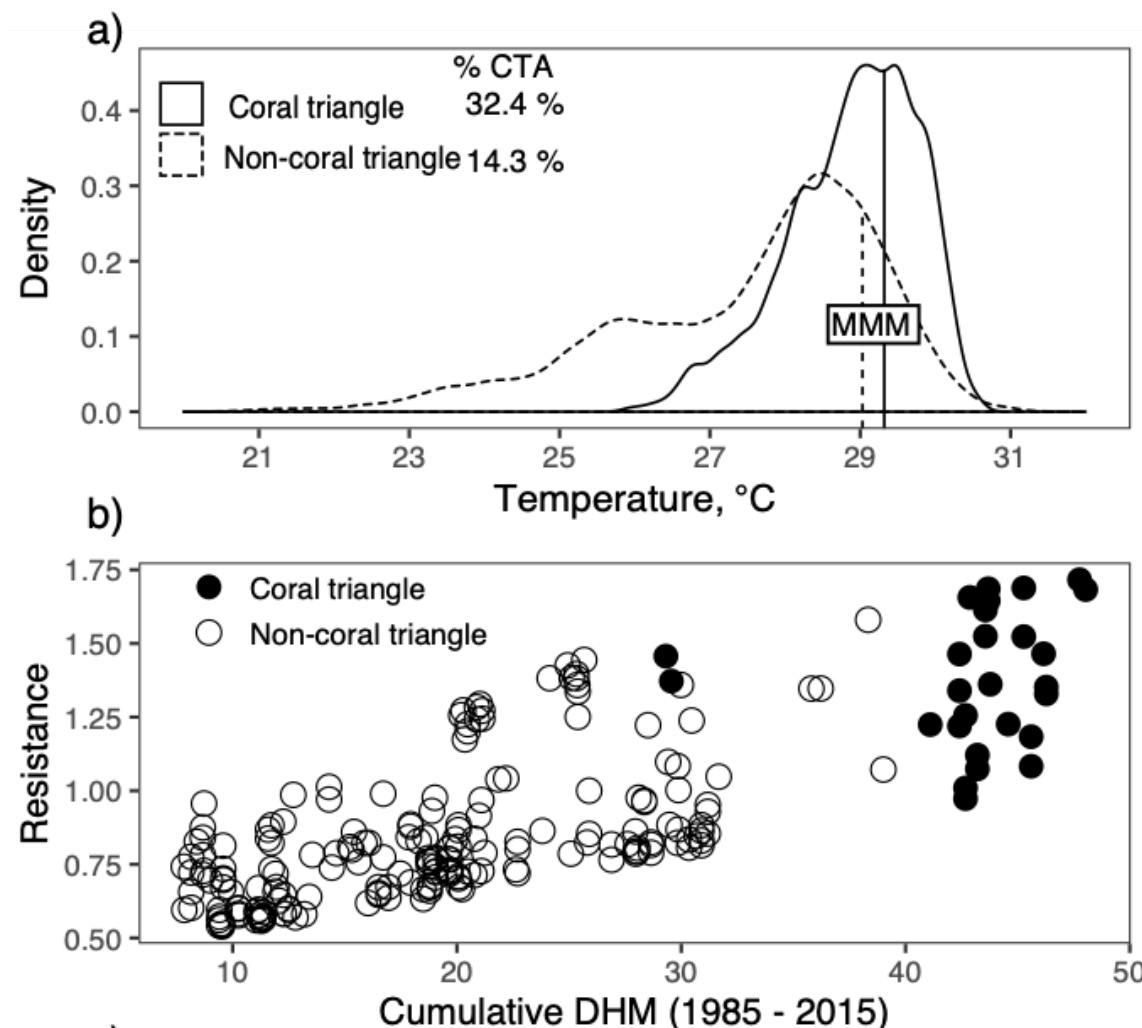

c)

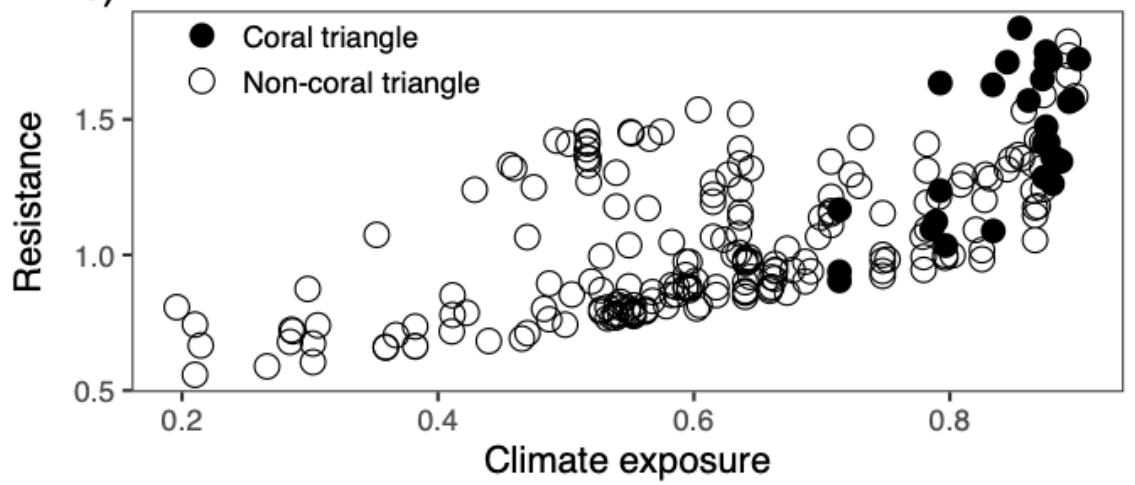

Figure 2. Temperature distributions, exposure, and coral resistance. The (a) density of temperature distributions of the 27 sites in and 199 sites outside the Coral Triangle based on monthly temperatures from 1985 to 2015. (b) Resistance as a function of the cumulative thermal anomaly (CTA) exposure model, and (c) resistance as a function of the multivariate climate exposure (CE) model in and outside the Coral Triangle. $\mathrm{MMM}=$ mean monthly summer maximum temperatures and $\mathrm{CTA}=$ cumulative thermal anomalies based on the cumulative degree heating months. 


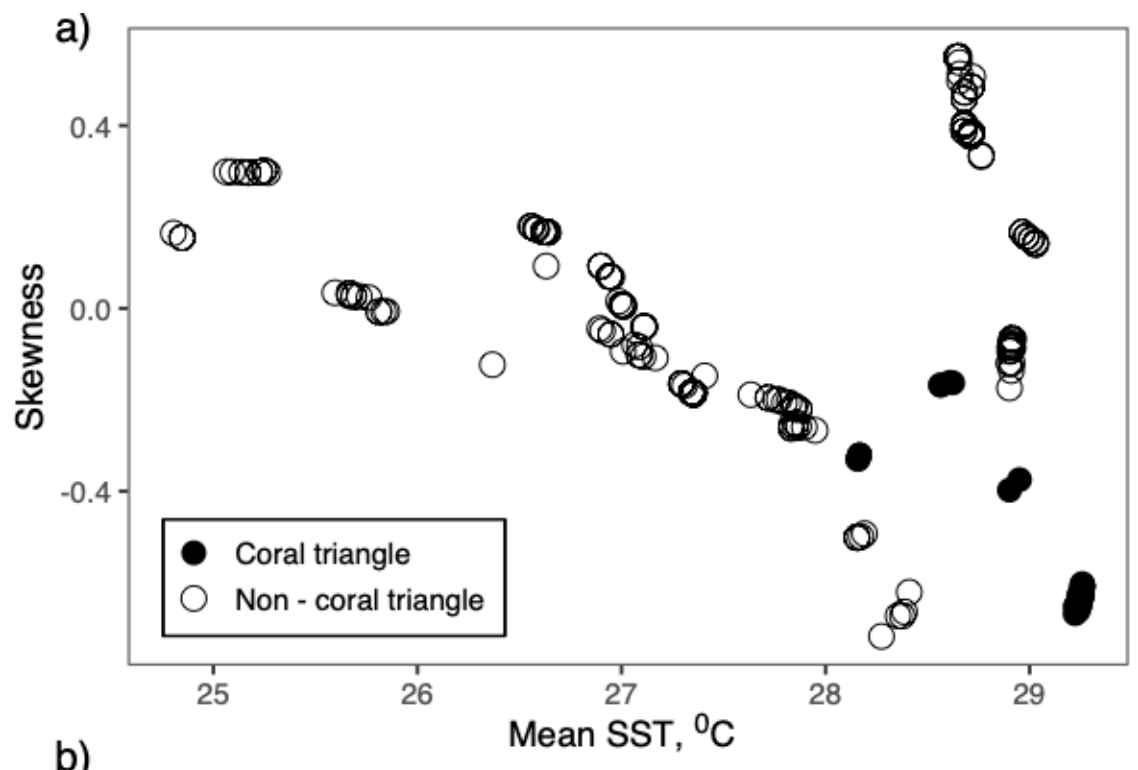

b)

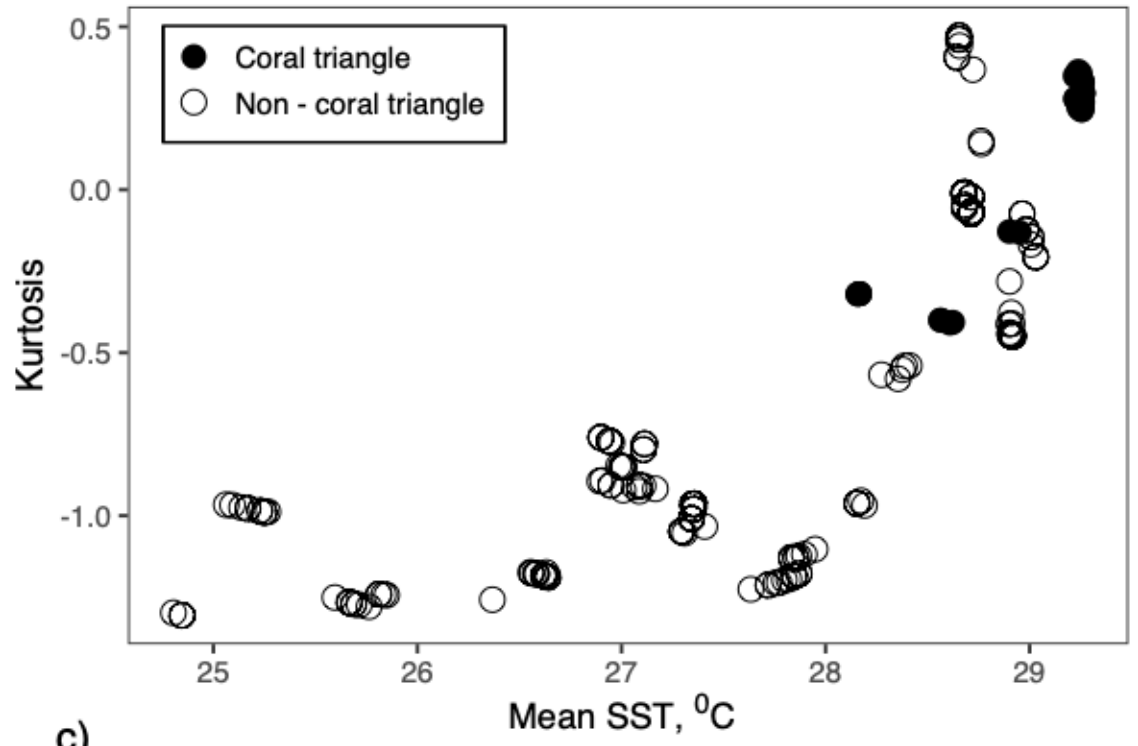

c)

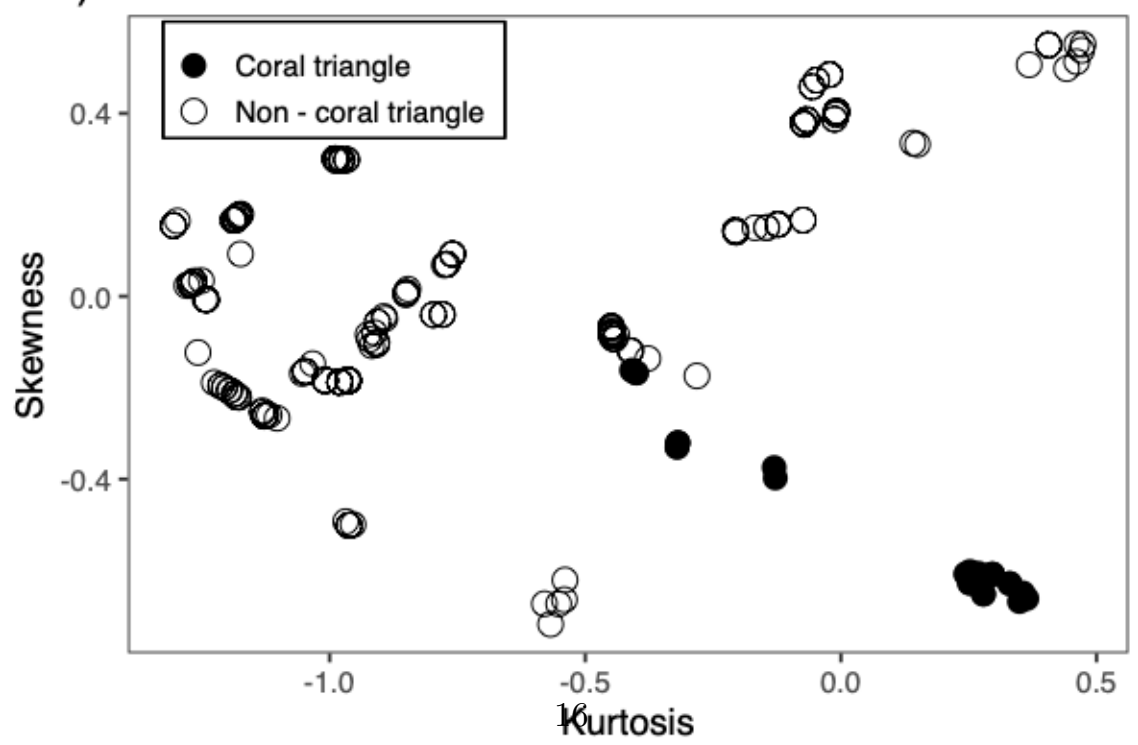


Figure 3. Scatterplots between the three sea-surface temperature metrics. Relationships between mean SST, kurtosis, and skewness variables used to test the factors influencing resistance models based on 226 study sites.

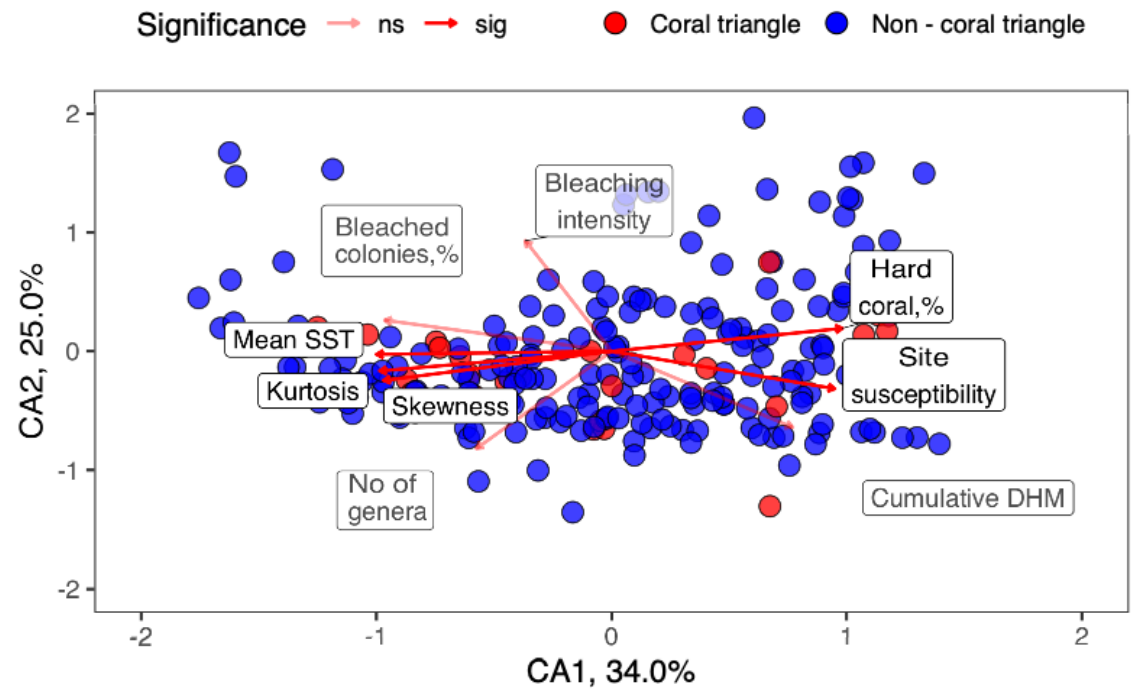

Figure 4. Community correspondence analysis (CCA) of the coral communities in and out of the Coral Triangle region. Summary of the two axes and comparison between the Coral and non-Coral Triangle are presented in Table 2 and not statistically different.
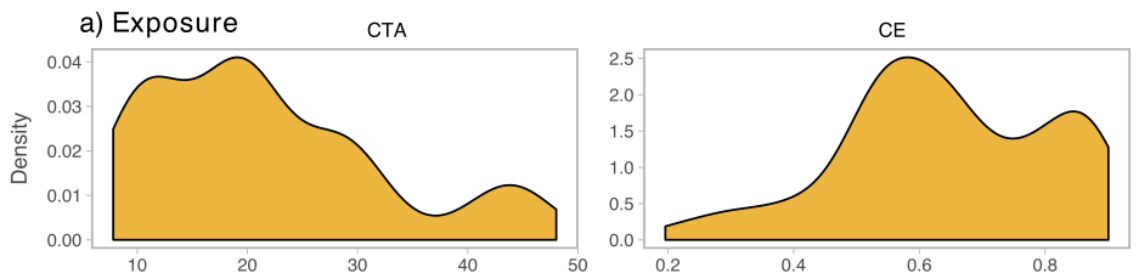

b) Sensitivity
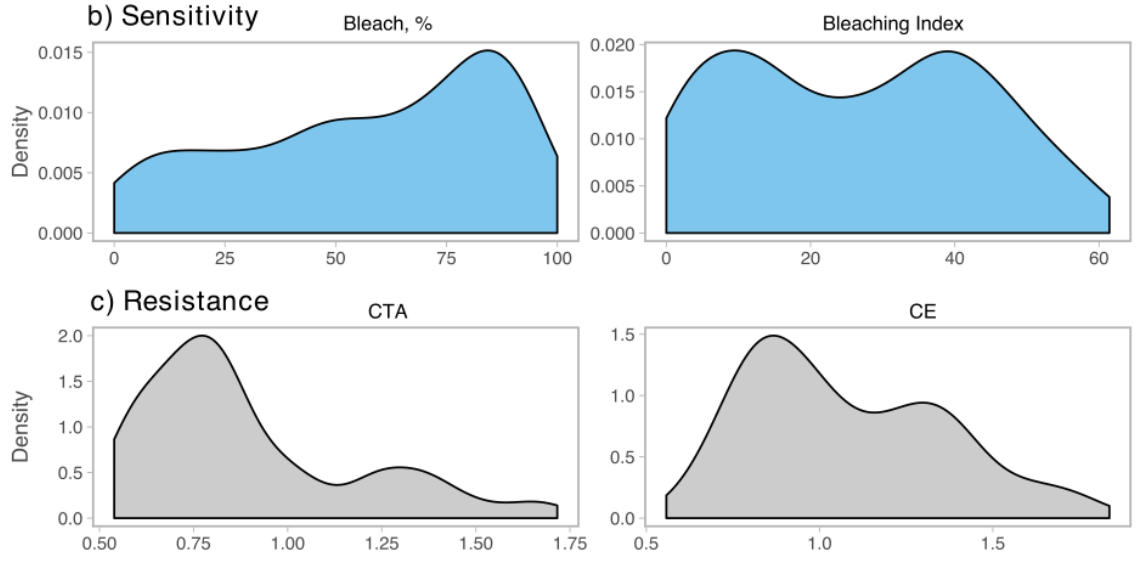

Supplementary Figure 1. Density plots showing the distribution of (a) the two exposure models, (b) the two metrics of ecological sensitivity, and (c) the two resistance models calculated from each exposure model. 
Percent bleaching was used as the ecological sensitivity metric in each resistance model. Density plots show values from the 226 sites included in this study from 12 countries across the Indo-Pacific. 